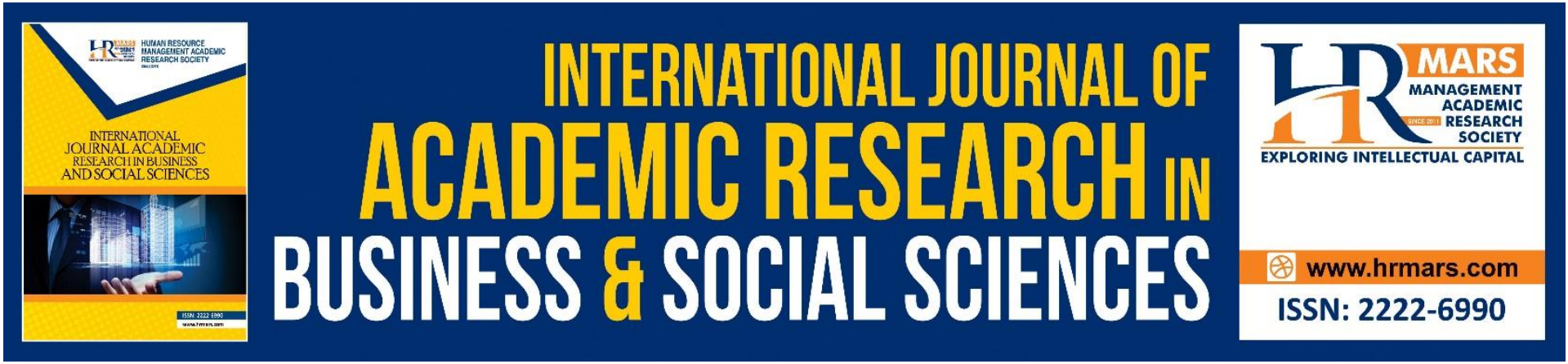

\title{
Estimating Severity of SOCSO's Invalidity Pension Scheme (IPS)
}

Mohd Zaki Awang Chek, Isma Liana Ismail, Nur Faezah Jamal

To Link this Article: http://dx.doi.org/10.6007/IJARBSS/v11-i4/9708

DOI:10.6007/IJARBSS/v11-i4/9708

Received: 11 February 2021, Revised: 14 March 2021, Accepted: 31 March 2021

Published Online: 19 April 2021

In-Text Citation: (Chek et al., 2021)

To Cite this Article: Chek, M. Z. A., Ismail, I. L., \& Jamal, N. F. (2021). Estimating Severity of SOCSO's Invalidity Pension Scheme (IPS). International Journal of Academic Research in Business and Social Sciences, 11(4), 618-625.

Copyright: () 2021 The Author(s)

Published by Human Resource Management Academic Research Society (www.hrmars.com)

This article is published under the Creative Commons Attribution (CC BY 4.0) license. Anyone may reproduce, distribute, translate and create derivative works of this article (for both commercial and non-commercial purposes), subject to full attribution to the original publication and authors. The full terms of this license may be seen

at: http://creativecommons.org/licences/by/4.0/legalcode

Vol. 11, No. 4, 2021, Pg. 618 - 625

http://hrmars.com/index.php/pages/detail/IJARBSS

JOURNAL HOMEPAGE

Full Terms \& Conditions of access and use can be found at http://hrmars.com/index.php/pages/detail/publication-ethics 


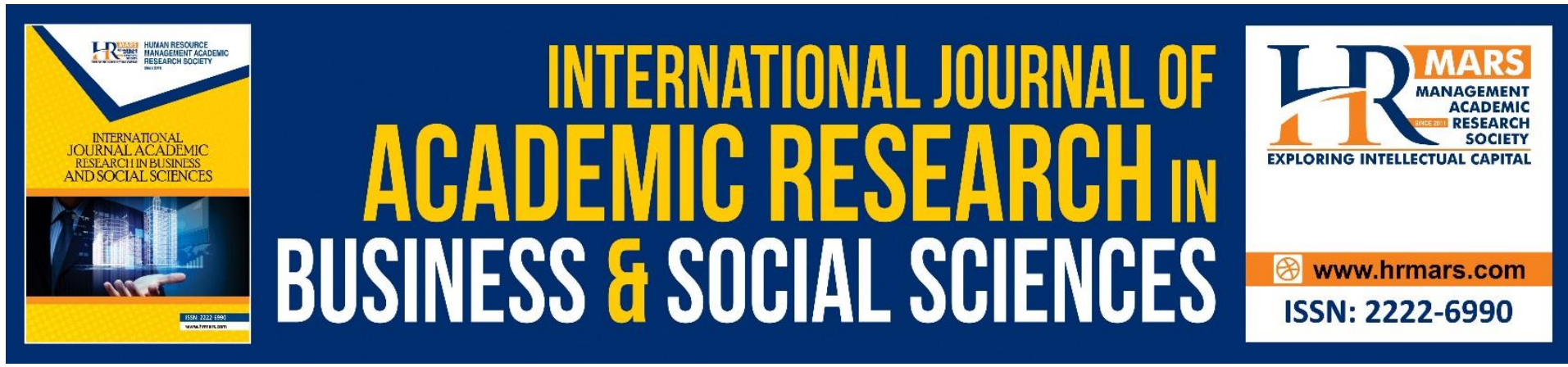

\title{
Estimating Severity of SOCSO's Invalidity Pension Scheme (IPS)
}

\author{
Mohd Zaki Awang Chek, Isma Liana Ismail, Nur Faezah Jamal \\ UiTM Perak Branch, Malaysia
}

\begin{abstract}
Social insurance was introduced in Malaysia in 1971 through Social Security Organisation (SOCSO). SOCSO administer 4 schemes such as Employment Injury Scheme (EIS), Employment Insurance Scheme, Self- Employment and Invalidity Pension Scheme (IPS).

The main objective of this study to estimate the severity of SOCSO's IPS from 2019 till 2023 by using single linear regression. Statistically, the total IPS's claims payment had steadily increased since 1971 to 2014. On average, the total claims payment increased at a rate of $10 \%$ every year.

This study suggested that a large part of the increase in IPS claims could be explained by population which active contributors, and the increase result from equalization of IPS services across the country. In addition, it seems that the claims of low and high care levels depend on different factors. The increase in IPS claims should be monitored carefully to identify underlying factors and to ensure sustainability of the funding system.
\end{abstract}

Keywords: Severity, SOCSO, IPS, Employment Injury Scheme, ESSA.

\section{Introduction}

SOCSO was established through Employees' Social Security Act (ESSA) in 1971 to provide social insurance and protections such as Employment Injury Scheme (EIS) and Invalidity Pension Scheme (IPS) to all employees in Malaysia. The source of SOCSO's collection comes from both parties, namely the employers and the employees. Currently, the total amount of contribution collected against benefits and claim payouts made by SOCSO from 2002 to 2013. SOCSO provides compensation to the eligible employees who receive lifetime pensions due to occupational uncertainties. This is one of the factors which has contributed to the drop in the SOCSO fund since 2008 (Chek et al., 2012; Chek et al., 2018b, 2018a, 2019b, 2019a).

\section{Literature Review}

The regression analyses have been employed in numerous researches since these few years because such methods offer useful information for data analyses (Levinsky et al., 2001).

As such this section unfolds the discussion of several researches pertaining to collection of funds and payments of claims practiced by both the governmental and non-government insurance industry. Furthermore, the approaches of regression have been employed by these 
studies in examining data, besides estimating the results of fund collection, as well as expenses (Venema, 2007).

Kidder (1992) investigated the impacts of a hospice event upon Medicare Part A expenses for the initial three years. As a result, the initial three-year hospice event saw that Medicare had managed to save $\$ 1.26$ for expenses incurred in Part A. Nevertheless, long-term eligibility and improvement in quality due to provision of benefits are some of the noted significances.

On the other hand, Ferraz et al (2008) investigated the use and the expenses of healthcare among Brazilians who received coverage from private healthcare schemes four years prior to death. For that purpose, data were retrieved from death certificates and files obtained from medical scheme agent, hence the subjects were comprised of 274 health scheme recipients deceased in years 1998, 1999, and 2000. In brief, vast healthcare capitals had been used by Brazilian private medical scheme subjects in 2007. Therefore, some strategies have to be devised in order to boost provision of healthcare capitals among those in need of care.

The literature depicts some essential aspects of the study from the stance of inferential. Besides, crucial approaches taken to overcome some issues in present organizations are elaborated as well. Thus, this study adopts inferential statistics to estimate the severity of Invalidity Pension Scheme (IPS) (Chek et al., 2018b).

\section{Methodology}

\section{Research Design}

Trend analysis of SOCSO's IPS claims payment made was analysed. Research design was adopted for this study which time series data (1985-2018) study using single regression analysis was employed for the study on predicted future claims payment within a span of five years, from 2019-2023 (Sekaran et al., 2013). The type of investigation selected for this research was causal research to identify cause-and-effect relationship. this type of investigation on claims payments' influence on contribution rate is most suitable when a study seeks to define the cause of insufficient claims payment (Zikmund et al., 2013).This study was conducted on longitudinal (also known as time series) time horizon since the data were gathered from 1985 to 2018 from SOCSO's archive. Longitudinal study involves the collection of data across more than one point of time in order to estimate severity of SOCSO's IPS (Sekaran \& Bougie, 2013).

\section{Sampling Design}

Sampling design is the method, or generally referred to as the technique, used to select sample units for measurement. Prior to selecting the sampling design methods for a research, it is necessary to thoroughly define the population. These have an impact on deciding the sample design methods that are suitable.

In this study, the sampling design which includes the elements of population, sampling frame, sampling technique, and sample size used is justified below. The population for the study comprised all Malaysian employees in the country. This is because all employees in Malaysia are required to register with SOCSO as stated under the (ESSA) Act 4 (Malaysian Government, 2006).

The sampling frame included all Malaysian employees who had registered with SOCSO, as mentioned earlier. This included all active employees who were earning a gross monthly salary of less than RM3,000.00 as regulated under the ESSA Act 4 (Malaysian Government, 2006). In this study, all Malaysian active employees were included. Therefore, a census was 
carried out in this study whereby every active registered employee in Malaysia was evaluated. This is known as a complete enumeration, referring to the complete count for this study.

As stated in the time horizon section, this study was conducted on a time series basis since the data were gathered from 1985 to 2018 from e SOCSO's archive. This is subject to availability and confidentiality of the required data from the relevant SOCSO Department.

\section{Data Analysis}

Data analysis is the application of reasoning to understand the data that have been gathered (Zikmund et al., 2013). The inferential statistics procedures were conducted with Microsoft Excel and SPSS computer package. The linear equation shown on the chart represents the relationship between year as $(x)$ and benefit claim payments as $(y)$ for the compound in solution.

In this study, the data gathered comprised 33 observations from 1985 to 2018 . When a line was fitted through the scatter plot, the regression line revealed the estimated claim payments for a given year. The distance between the regression line and the data point represents the unexplained variation, which is also called the residual $r^{2}$.

The method of least squares is used to minimise the residual. The equation provides an evaluation of the validity and usefulness (Verhoef \& Donkers, 2001). Standard linear regression models with standard estimation techniques make several assumptions about the predictor variables, the response variables, and their relationship. Generally, these extensions make the estimation procedure more complex and time-consuming, and may also require more data in order to produce an equally precise model.

Field (2005) stated that the following seven assumptions are made by standard linear regression models with standard estimation techniques, namely as sample size, linear relationship, multivariate normality, homoscedasticity, little multicollinearity, outliers and no auto- correlation.

\section{Findings and Analysis}

This study has also analysed the trends between claims payment and the number of years. SOCSO's IPS claims payment is the dependent variable, while year is the independent variable.

\section{Simple Linear Regression Assumptions: Claims Payment}

As stated in the previous discussion, seven assumptions validated before the regression analysis for SOCSO's IPS claims payment can be conducted. Furthermore, the result of simple linear regression for predicted SOCSO's IPS claims payment is presented from 2019 until 2023 after all the seven assumptions above have been checked and are confirmed to be valid.

\section{Regression in Claims Payment}

This study analyses two empirical single regression models for contribution collection and claims payments respectively. Since the original data relating to the claims payment is skewed to the right, it is transformed into logarithm. Since the computed SOCSO's IPS claims payment data meet all assumptions towards the simple linear regression, this section discusses the simple linear regression of forecasted claims payment from 2019 until 2023, as shown in Table 1 and Figure 1 accordingly. The predicted simple regression for SOCSO's IPS claims payment is conducted as below. 
Table 1. Forecasted Claims Payment from 2019 until 2023

\begin{tabular}{|l|r|}
\hline \multicolumn{1}{|c|}{ Year $(x)$} & $\begin{array}{r}\text { Forecasted Claims Payment, y (RM) } \\
y=16.526 * e^{0.164 . x}\end{array}$ \\
\hline 2019 & $\mathbf{5 , 1 4 0 , 6 5 0 , 4 5 5 . 8 8}$ \\
2020 & $\mathbf{6 , 0 5 6 , 7 8 7 , 9 5 6 . 0 0}$ \\
2021 & $\mathbf{7 , 1 3 6 , 1 9 4 , 2 7 3 . 0 0}$ \\
2022 & $\mathbf{8 , 4 0 7 , 9 6 6 , 2 4 8 . 0 0}$ \\
2023 & $\mathbf{9 , 9 0 6 , 3 8 6 , 1 9 4 . 0 0}$ \\
\hline
\end{tabular}

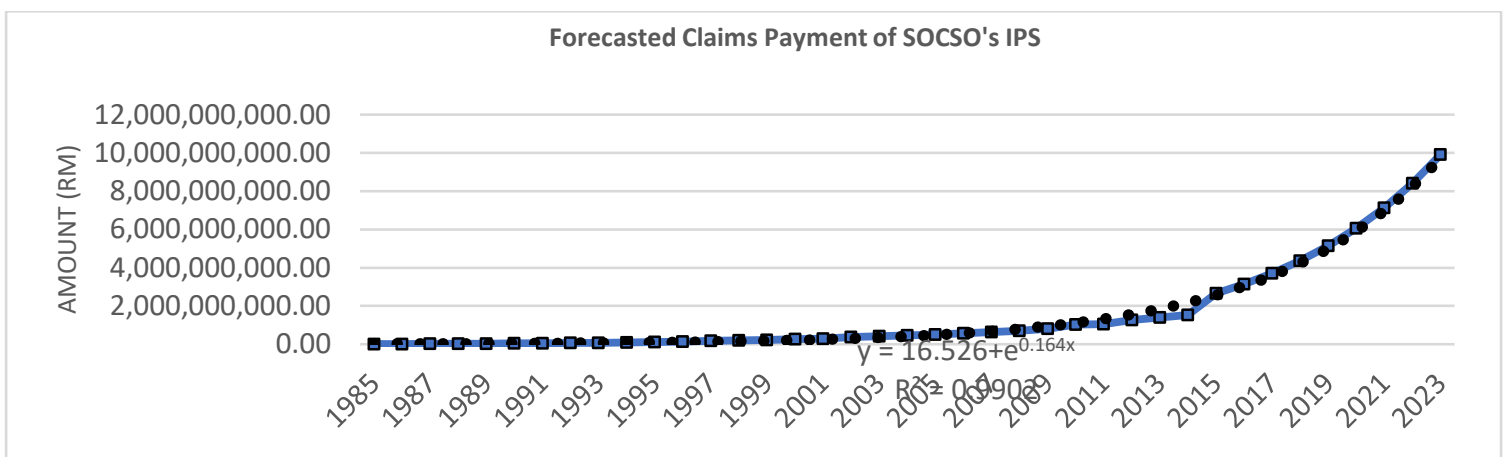

Figure 1. Forecasted Claims Payment from 2019 until 2023

Table 1 and Figure 1 provide a scatter diagram for SOCSO's IPS. This scatter diagram demonstrates a perfect relationship between the computed amounts of claims payment against the year. In the SPSS output, the prediction equation for claims payment is,

$$
\text { Claims Payment }, y=16.526+\mathrm{e}^{0.164 \mathrm{x}}
$$

This computed equation shows that the claims payment is predicted to increase significantly by an amount of RM16,526, 000 when the independent variable year increases by one unit. Table 10 shows an ANOVA Table which illustrates that this model is significantly better at predicting future SOCSO's IPS claims payment, As the F- ratio is 1267.257, which is a highly significant value $(p<0.001)$. Again, this result indicates that the model has significantly improved the ability to predict SOCSO's IPS claims payment from 2019 until 2023.

The R-squared for eq. 3 is $98 \%$. Evidently, $2 \%$ of the variation cannot be explained by year. This can be attributed to other factors that have not been included in the equation (Greene, 2010). This study is performed to analyse the relationship and the trend of SOCSO's IPS claims payment with the independent variable, namely the year. The linear regression indicate that the predicted claims payment exponentially increases from the year 2019 until 2023.

\section{Conclusion}

According to the annual report issued by SOCSO, it appears that there is a deficit of the IPS fund distributed. In 2002, the total distribution was recorded at RM369.8 million. The threefold increase in the next five years brings the total allocation to RM633.24 million. In 2014, a total of RM1.5 billion in IPS funding was successfully distributed accordingly to eligible claimants in Malaysia via the seven types of benefits mentioned (Seng, 2014).

The insufficiency of contribution collected can be seen since 2010, where the trend shows an increasing number of claim payments over the years. This shows that the current contribution rate applied by SOCSO is deficient. Findings based on analyses of severity show that the claim payments under the IPS distributed according to the seven (7) types of benefits 
from 2002 to 2014 form the largest share and given to the Invalidity Pension and Grant, totaling $40 \%$ of the total fund collected (ILO, 2013).

Furthermore, based on the amounts of SOCSO's IPS, it is found that the amount of claims increases exponentially every year. This is a critical situation where the current contribution rate is insufficient to fulfil the obligation to meet IPS claim payments. In this regard, SOCSO should look into applying an optimal contribution rate for its IPS (ILO, 2013).

The above analyses were done as preliminaries and the main analysis is to model an efficient social insurance plan. This is important and SOCSO should place emphasis on this. In this study also, the contribution fund collection and budgeted claim payments are predicted based on available past information. It concerns the amount of losses, and the frequency exposure to risk. Furthermore, the contribution fund collection and budgeted claim amounts were used as the basis to model an adequate contribution rate for SOCSO's IPS (Kaas \& Goovaerts, 2009).

\section{Acknowledgement}

This study was partially supported by UiTM Perak Branch. We thank our colleagues from Universiti Kebangsaan Malaysia (UKM) and Social Security Organization (SOCSO) who provided insight and expertise that greatly assisted the study. We thank Prof. Dr. Zuriah Ab. Rahman for assistance, and Prof. Dr. Nuriszura Ismail for comments that greatly improved the manuscript.

\section{Corresponding Author}

Mohd Zaki Awang Chek.

Universiti Teknologi MARA, Malaysia.

Email: mohdz220@uitm.edu.my

\section{References}

Chek, M. Z. A., Ahmad, A. B., Ridzwan, A. N. A. A., Jelas, I. M., Jamal, N. F., Ismail, I. L., Zulkifli, F., \& Noor, S. I. M. (2012). Univariate time series modeling and an application to future claims amount in SOCSO's invalidity pension scheme. AIP Conference Proceedings, 1482. https://doi.org/10.1063/1.4757501

Chek, Mohd Zaki Awang, Ismail, I. L., \& Jamal, N. F. (2019a). Assessing Contribution Collection: A Case of SOCSO's IPS. International Journal of Recent Technology and Engineering, 8(2S11), 621-623. https://doi.org/10.35940/ijrte.b1096.0982s1119

Ferraz, M. B., Miranda, I. C., Padovan, J., De Soárez, P. C., \& Ciconelli, R. (2008). Health care costs in the last four years of life for private health plan beneficiaries in Brazil. Pan American Journal of Public Health, 24(2), 120-126. http://www.scopus.com/inward/record.

Field. (2005). Factor analysis using SPSS. Retrieved December, 8057, 1-14. https://doi.org/10.1016/B978-0-444-52272-6.00519-5

Greene, W. (2010). The linear regression model. Econometric Analysis, 7th Edition. http://people.stern.nyu.edu/wgreene/MathStat/GreeneChapter2.pdf

ILO. (2013). The 9th Actuarial Valuation Report.

Kaas, R., \& Goovaerts, M. (2009). Modern Actuarial Risk Theory. https://doi.org/10.1007/9783-540-70998-5

Kidder, D. (1992). The effects of hospice coverage on medicare expenditures. Health Services Research, 27(2), 195-217. 
Levinsky, N. G., Yu, W., Ash, A., Moskowitz, M., Gazelle, G., Saynina, O., \& Emanuel, E. J. (2001). Influence of age on Medicare expenditures and medical care in the last year of life. Journal of the American Medical Association, 286(11), 1349-1355.

Malaysian Government. (2006). Employees' Social Security Act 1969 (Issue January). The Commissioner of Law Revision, Malaysia.

Sekaran, U., \& Bougie, R. (2013). Research Methods for Business (6th ed.). Wiley.

Seng, S. C. (2014). Social Security : Challenges and issues (No. 2014-1).

Venema, A. (2007). Monitoring occupational accidents in the Netherlands: Does it work for prevention? Safety Science Monitor, 11(2), 1-8.

Verhoef, P. C., \& Donkers, B. (2001). Predicting customer potential value an application in the insurance industry. Decision Support Systems, 32(2), 189-199.

https://doi.org/10.1016/S0167-9236(01)00110-5

Zikmund, W. G., Babin, B. J., Carr, J. C., \& Griffin, M. (2013). Business Research Methods (9th ed.). South- Western Cengage Learning.

Ferraz, M. B., Miranda, I. C., Padovan, J., De Soárez, P. C., \& Ciconelli, R. (2008). Health care costs in the last four years of life for private health plan beneficiaries in Brazil. Pan American Journal of Public Health, 24(2), 120-126. Retrieved from http://www.scopus.com/inward/record.

Field. (2005). Factor analysis using SPSS. Retrieved December, 8057, 1-14. https://doi.org/10.1016/B978-0-444-52272-6.00519-5

Frees, E. W. (2011). Regression modeling with actuarial and financial applications. Scandinavian Actuarial Journal, 2011(4), 319-319.

https://doi.org/10.1080/03461238.2010.484567

Greene, W. (2010). The linear regression model. Retrieved February 1, 2015, from http://people.stern.nyu.edu/wgreene/MathStat/GreeneChapter2.pdf

ILO. (2013). The 9th Actuarial Valuation Report. Bangkok.

Kaas, R., \& Goovaerts, M. (2009). Modern Actuarial Risk Theory. https://doi.org/10.1007/9783-540-70998-5

Kidder, D. (1992). The effects of hospice coverage on medicare expenditures. Health Services Research, 27(2), 195-217.

Kutner, M. H., Nachtsheim, C. J., \& Neter, J. (2008). Applied linear regression models (4th. ed.). Singapore: Mc Graw Hill.

Levinsky, N. G., Yu, W., Ash, A., Moskowitz, M., Gazelle, G., Saynina, O., \& Emanuel, E. J. (2001). Influence of age on Medicare expenditures and medical care in the last year of life. Journal of the American Medical Association, 286(11), 1349-1355.

Lin, D. Y. (2000). Linear regression analysis of censored medical costs. Biostatistics (Oxford, England), 1(1), 35-47. https://doi.org/10.1093/biostatistics/1.1.35

Lubitz, J. D., \& Riley, G. F. (1993). Trends in Medicare payments in the last year of life. The New England Journal of Medicine, 328(15), 1092-1096. https://doi.org/10.1056/NEJM199304153281506

Malaysian Government. (2006). Employees' Social Security Act 1969. Kuala Lumpur: The Commissioner of Law Revision, Malaysia.

Muhammad, N. M. N. (2013). Personal financial planning (1st ed.). Kuala Lumpur: UiTM Press.

Samson, D., \& Thomas, H. (1987). Linear models as aids in insurance decision making: The estimation of automobile insurance claims. Journal of Business Research, 15(3), 247256. https://doi.org/10.1016/0148-2963(87)90027-0

Sekaran, U., \& Bougie, R. (2013). Research Methods for Business (6th ed.). Italy: Wiley. 
Seng, S. C. (2014). Social Security : Challenges and issues (No. 2014-1). Kuala Lumpur. SOCSO. (2014). SOCSO Annual Report 2013. Kuala Lumpur.

Taylor, G. C. (1987). Regression models in claims analysis. Retrieved February 1, 2015, from http://www.beanactuary.org/pubs.pdf

Venema, A. (2007). Monitoring occupational accidents in the Netherlands: Does it work for prevention? Safety Science Monitor, 11(2), 1-8.

Verhoef, P. C., \& Donkers, B. (2001). Predicting customer potential value an application in the insurance industry. Decision Support Systems, 32(2), 189-199. https://doi.org/10.1016/S0167-9236(01)00110-5

Zhou, X.-H. (2002). Inferences about population means of health care costs. https://doi.org/10.1191/0962280202sm290ra

Zikmund, W. G., Babin, B. J., Carr, J. C., \& Griffin, M. (2013). Business Research Methods (9th ed.). Canada: South- Western Cengage Learning. 